\title{
International/Resident Traveling Fellowship Notice 2021
}

\section{Resident Traveling Fellowship in Pediatric Neurosurgery}

The Joint Pediatric Neurosurgery Section of the American Association of Neurological Surgeons and Congress of Neurological Surgeons offers a traveling fellowship for residents in accredited North American neurosurgical training programs. The fellowship is intended to cover the traveling and living expenses for one month for a resident who wishes to obtain additional experience in pediatric neurosurgery during residency. The one-month fellowship can be spent at any pediatric neurosurgery program within North America to pursue an activity which broadens the resident's exposure to pediatric neurosurgery, including observation at a clinical or research center, participation in a research project, or any other relevant activity. Fellowships are awarded on the basis of a competitive evaluation by a committee of the Joint Pediatric Section. The maximum fellowship stipend is $\$ 2500$.

The application must include:

1. a statement defining the purpose of the proposed fellowship;

2. written permission from the applicant's residency program director to pursue the 1-month fellowship if it is awarded;

3. a letter of acceptance from the pediatric neurosurgical program where the applicant will seek the fellowship;

4. the applicant's current curriculum vitae.

The deadline for application submission is November 5th, 2021. The completed application should be e-mailed to:

Ahn.edward@mayo.edu

Ed Ahn, MD

Senior Associate Consultant

Professor of Neurosurgery

Mayo Clinic

\section{International Traveling Fellowship in Pediatric Neurosurgery}

The Joint Pediatric Neurosurgery Section of the American Association of Neurological Surgeons and Congress of Neurological Surgeons offers an international traveling fellowship for neurosurgeons who, at the time of their application, are either training in a residency program outside the United States and Canada or who have completed residency training outside the United States and Canada within the past five years.

The fellowship will cover the traveling and living expenses for a three-month period to be spent observing the activities of an established Pediatric Neurosurgical service of the applicant's choosing in the United States or Canada. Fellowships will be awarded yearly on the basis of a competitive evaluation by a committee of the Pediatric Section at the annual meeting in December. The maximum fellowship stipend is $\$ 7500$.

The application must include:

1. a statement defining the purpose of the proposed fellowship;

2. a letter of recommendation from the applicant's current neurosurgical program director;

3. a letter of acceptance from the institution where the applicant intends to take the fellowship, confirming the description of the fellow's potential activities during the period of the award;

4. the applicant's current curriculum vitae.

The deadline for application submission is November 5th, 2021. The completed application should be emailed to:

Ahn.edward@mayo.edu

Ed Ahn, MD

Senior Associate Consultant

Professor of Neurosurgery

Mayo Clinic 


\section{The AANS/CNS Pediatric Traveling Fellowship: Message to Programs Interested in Hosting North American and International Fellows.}

The Joint Pediatric Neurosurgery Section of the American Association of Neurological Surgeons and Congress of Neurological Surgeons has established 1 to 3-month traveling fellowships for North American residents and international neurosurgeons, as stipulated in the fellowship announcement (https://pedsneurosurgery.org/grants-fellowships/resident-traveling-fellowship-in-pediatric-neurosurgery/ or https://pedsneurosurgery.org/grants-fellowships/international-traveling-fellowship-in-pediatric-neurosurgery/).

The deadline for receipt of applications is November 5, 2021.
The Section would like to give all North American Pediatric Neurosurgery programs the opportunity to participate in hosting domestic or international pediatric traveling fellows. Information about interested programs will be published on the Section website. To have their information published, the programs are asked to fill out an online application provided at https://pedsneurosurgery.org/grants-fellowships/sponsor-institution-application/, which should then be emailed to Ed Ahn at ahn.edward@mayo. edu. We would like to emphasize that these short-term fellowships are distinct from the formal one-year Pediatric Neurosurgery fellowships offered at select programs. There is no financial obligation for the host department, as the stipend provided by the Section should cover the fellow's expenses. 